\title{
Real-World Adherence to Antiretroviral Therapy Among HIV-1 Patients Across the United States
}

\author{
Grace A. McComsey · Melissa Lingohr-Smith • Rachel Rogers • \\ Jay Lin · Prina Donga
}

Received: June 28, 2021 / Accepted: August 3, 2021 / Published online: August 14, 2021

(C) The Author(s) 2021

\begin{abstract}
Introduction: Recent changes in antiretroviral therapies (ARTs) may have affected medication adherence of people living with human immunodeficiency virus-1 (HIV-1). In this study adherence to ART regimens among patients with HIV-1 (PWH) across the US during a recent time period was examined and study findings were stratified by US region and state.

Methods: A retrospective observational study using the Symphony Health Solution Integrated Dataverse database was conducted. Patients $\geq 18$ years of age who had a diagnosis of HIV-1 (without an HIV-2 diagnosis) and who were treated with ART between July 2017 and

Supplementary Information The online version contains supplementary material available at https:// doi.org/10.1007/s12325-021-01883-8.
\end{abstract}

G. A. McComsey

University Hospitals of Cleveland and Case Western Reserve University, Cleveland, OH, USA

e-mail: Grace.McComsey@UHhospitals.org

R. Rogers · P. Donga ( $\square)$

Janssen Scientific Affairs LLC, Titusville, NJ, USA

e-mail: PDonga@ITS.JNJ.comR. Rogers

e-mail: rroger17@its.jnj.com

M. Lingohr-Smith $\cdot$ J. Lin

Novosys Health, Green Brook, NJ, USA

M. Lingohr-Smith

e-mail: melissa.smith@novosyshealth.comJ. Lin

e-mail: jay.lin@novosyshealth.com
September 2018 (first pharmacy record: index date) were selected from the data source. Both patients who had not been previously treated with ART and those who were treatment experienced were included. Patients were required to have $\geq 1$ medical/pharmacy record $\geq 12$ months after their index date (follow-up period). Patient characteristics were examined during a 12-month preindex period. During the follow-up, medication adherence, measured as the proportion of days covered (PDC), was examined for all patients and stratified by US region and state.

Results: Among 206,474 adult PWH treated with ART, mean age was 47.9 years, $73.4 \%$ were male, and $30.0 \%$ were Caucasian. The most prevalent comorbid conditions were hyperlipidemia $(25.1 \%)$, depressive disorders (14.8\%), and type 2 diabetes (12.1\%). During the followup period, mean (standard deviation) PDC was $74.1 \%$ (25.9\%) among PWH across the US [Midwest: $74.4 \%$ (25.5\%); Northeast: $74.3 \%$ (26.1\%); South: $73.2 \%$ (26.3\%); West: $76.4 \%$ (24.8\%)]. Across all US regions, $>60 \%$ of PWH had adherence $<90 \%$ and $>40 \%$ had adherence $<80 \%$; the West had the highest adherent population.

Conclusions: Among PWH treated with ART across the US, a majority had suboptimal adherence. Implementation of strategies to improve ART adherence, including clinical consideration of ARTs with high genetic barriers to resistance, is needed in the US. 
Keywords: Adherence; Antiretroviral therapy; HIV-1; Regions; States; United States

\section{Key Summary Points}

Why carry out this study?

A previous US study by Benson et al. examined adherence to antiretroviral therapy (ART) of patients with human immunodeficiency virus-1 (HIV-1; PWH) treated between January 2015 and September 2017 and found an average adherence level of $72 \%$; their findings were stratified by US state, providing a state- and regional-level depiction of ART adherence for targeting intervention efforts

Since 2017, several ART medications, including single-tablet regimens (STRs), have been developed and approved by the US Food \& Drug Administration for the treatment of HIV-1; such changes in the treatment landscape of HIV-1 could potentially affect medication adherence, and further study of ART adherence is warranted

\section{What was learned from the study?}

In this large nationwide US study, including over 200,000 people diagnosed with HIV-1 and treated with ART during July 2017 through September of 2019, the average adherence to therapy was approximately $74 \%$; those in the West had the highest mean adherence (76\%) and those in the South, the lowest (73\%)

Across the US, a majority (approximately $60 \%$ ) of PWH had suboptimal adherence [proportion of days covered (PDC) < 90\%] to ART and $42 \%$ had poor adherence (PDC $<80 \%)$

Implementation of strategies to improve ART adherence, including clinical consideration of ARTs with high genetic barriers to resistance, is needed in the US

\section{INTRODUCTION}

Between 2013 and 2018, the estimated number of new diagnoses of human immunodeficiency virus (HIV) infections in the US (US) was approximately 38,000 annually [1, 2]. According to the most recent data available (2018) from the Centers for Disease Control and Prevention (CDC), approximately 1.2 million people are living with HIV in the US [3]. Without treatment, HIV infection leads to the development of acquired immunodeficiency syndrome (AIDS) and eventually death. The introduction of antiretroviral therapy (ART) in the late 1980s transformed the treatment of HIV, such that the disease could be pharmacologically managed. Highly active ART medications effectively inhibit HIV replication and thereby significantly reduce disease progression to AIDS, increase survival and quality of life, and block viral transmission [4-6]. However, to achieve sustained optimal viral suppression, a systematic review of numerous studies (2012-2016) of patients with HIV-1 (PWH) on ART regimens reported that a high level of adherence ( $\geq 90 \%)$ is necessary [7].

In 2019, the Pharmacy Quality Alliance, a nationally recognized organization in the US that provides consensus-based measures for medication safety, adherence, and appropriate use, also recommended $\geq 90 \%$ adherence to be considered as optimal for ART regimens [8]. The US Department of Health and Human Services (DHHS) guidelines for adults and adolescents living with HIV recommend multiple strategies to improve adherence to ART treatments, including providing uninterrupted access to care, motivation for ART initiation, the periodic assessment of adherence to ART and care, patient education on the importance of adherence, and the simplification of ART dosing, such as using a single-table regimen (STR) $[9,10]$. The use of STRs has been found in several studies to be associated with improved adherence to ART regimens versus multiple tablet regimens (MTRs) among PWH [7, 11-15] and in some studies was also found to be associated with improved outcomes, including higher levels of 
viral suppression, decreased hospitalizations, and lower medical costs $[7,11,14]$.

A previous US study by Benson et al. [16] examined adherence to ART of PWH treated between January 2015 and September 2017 and found an average adherence level of $72 \%$; their findings were stratified by US state, providing a state- and regional-level depiction of ART adherence for targeting intervention efforts. Since 2017, several ART medications, including STRs, have been developed and approved by the US Food and Drug Administration for the treatment of HIV-1; such changes in the treatment landscape of HIV-1 could potentially affect medication adherence. To address this topic, this study examined adherence to ART regimens among PWH across the US between July 2017 and September 2019; findings were stratified by US region and state.

\section{METHODS}

\section{Study Design and Data Source}

A retrospective observational study was conducted using data from the Symphony Health Solution Integrated Dataverse $\left(\mathrm{IDV}^{\circledR}\right)$ database from July 1, 2016, through September 30, 2019. The IDV $^{\circledR}$ database is a comprehensive source of longitudinal healthcare data for $>300$ million patients throughout the US and its territories. Each patient is assigned a unique encrypted identifier, and a patient matching process is used to consolidate data gathered from data suppliers into records of their medical, hospital, and prescription activity. The anonymous longitudinal data include patient demographic information, health plan characteristics, medical service use (i.e., diagnosis and procedure codes), and pharmacy dispensing data.

The data source used for this study is comprised of administrative healthcare records that are deidentified and certified to be fully compliant with the Health Insurance Portability and Accountability Act patient confidentiality requirements. Institutional review board approval to conduct this study was not required because the study used only deidentified patient records and did not involve the collection, use, or transmittal of individually identifiable data.

\section{Patient Selection}

Patients $\geq 18$ years of age who were treated with ART between July 2017 and September 2018 were selected from the IDV database. ART was defined as either a combination regimen of 1 core ART medication and $\geq 1$ other ART medication within a 14-day period following the pharmacy record of the core ART medication (MTR) or 1 STR. ART core medications included the integrase strand transfer inhibitors (INSTIs), dolutegravir and elvitegravir, the protease inhibitors, darunavir and atazanavir, and the non-nucleoside reverse transcriptase inhibitors (NNRTIs), efavirenz, doravine, and rilpivirine. The STRs included Atripla ${ }^{\circledR}$, Biktarvy $^{\circledR}$, Complera $^{\circledR}$, Genvoya $^{\circledR}$, Odefsey $^{\circledR}$, Stribild $^{\circledR}$, (Gilead Sciences, Inc.), Dovato ${ }^{\circledR}$, Juluca $^{\circledR}$, Triumeq $^{\circledR}$ (ViiV Healthcare), Symfi ${ }^{\circledR}$ (Viatris, Inc.), Delstrigo $^{\circledR}$ (Merck), and Symtuza ${ }^{\circledR}$ (Janssen Therapeutics). All ART medications were identified by IDV database-specific drug identifiers.

The date of the earliest pharmacy record for a core ART medication (with a record for another ART medication within 14 days) or STR was designated as the index date for a patient. Patients were required to have a diagnosis of HIV-1 based on the presence of an International Classification of Diseases, 10th Revision, Clinical Modification (ICD-10-CM) code indicating HIV-1 (B20, R75, and Z21) on a medical record during the 12-month baseline period prior to their index date or on their index date. Patients were also required to have $\geq 1$ medical/pharmacy record $\geq 12$ months after their index date (follow-up period) recorded in the data source to ensure that patients were not dropped from the database during the follow-up period. Patients were excluded from the study population if they had a diagnosis of HIV-2 (ICD-10CM code: B97.35) during any time of the study period or if they had missing gender, age, or US state information. Both patients who had not been previously treated with ART, defined as having no ART use during the 12-month baseline period, and those who were treatment 
experienced (i.e., with a pharmacy record for an ART medication during the baseline period) were included in the study population. The selection process of patients is shown in Fig. 1.

\section{Patient Demographic and Clinical Characteristics}

Patient demographic and clinical characteristics, including age, gender, race/ethnicity, insurance type, Quan-Charlson Comorbidity Index (CCI) score (modified by exclusion of HIV/AIDS diagnoses), and select comorbid conditions, were evaluated during patients' baseline period or on their index dates. All comorbid conditions were identified based on the presence of corresponding ICD-10-CM codes in medical records.

\section{Adherence to ART}

Adherence to index ART was measured during patients' 12-month follow-up period using the proportion of days covered (PDC). The PDC was calculated as the sum of days during the followup period that were covered by either $\geq 2$ ARTs

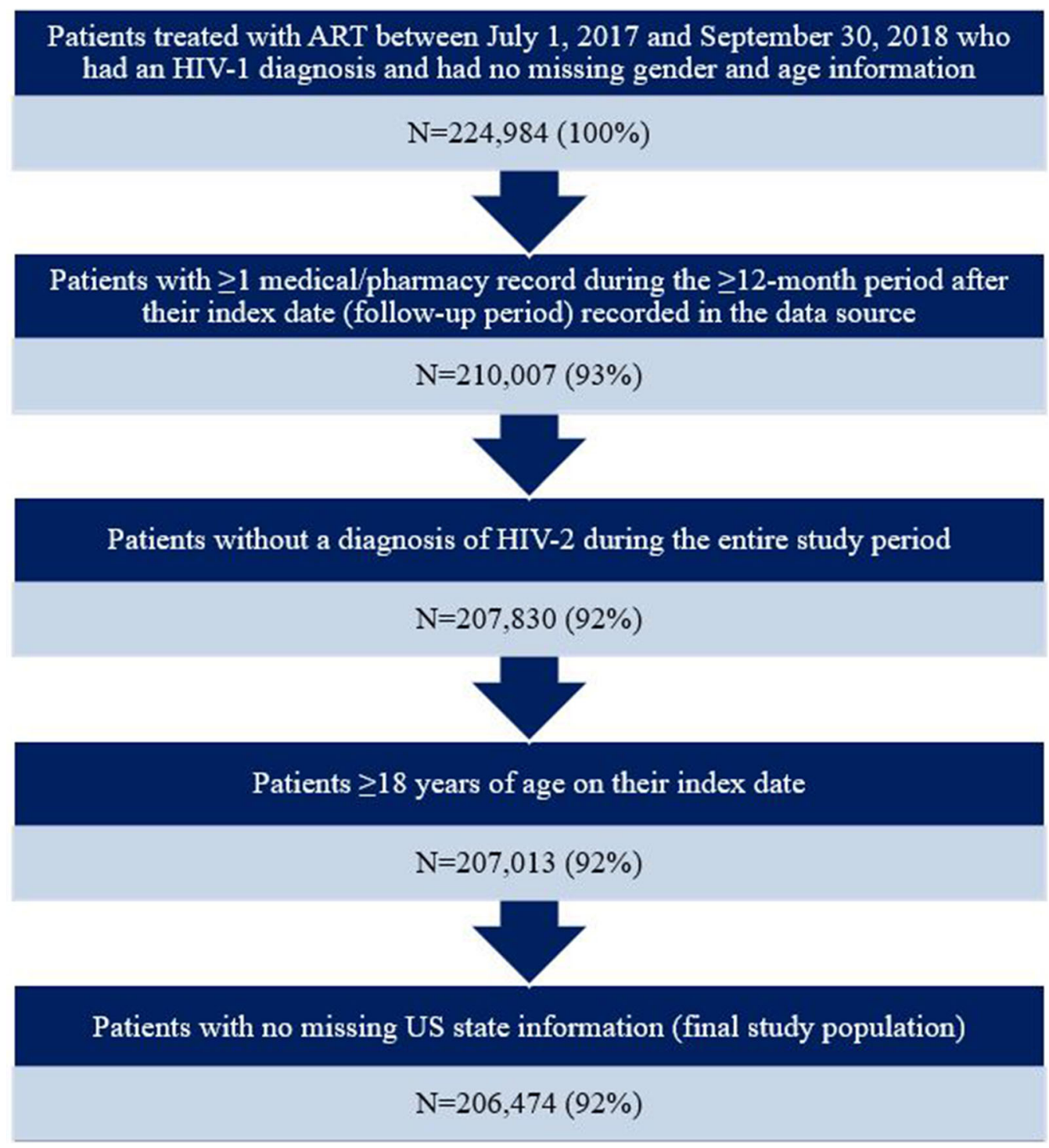

Fig. 1 Patient selection process. $A R T$ antiretroviral therapy 
Table 1 Demographic characteristics of study population, overall and stratified by US region

\begin{tabular}{|c|c|c|c|c|c|c|}
\hline Characteristic & $\begin{array}{l}\text { All } \\
N=206,474\end{array}$ & $\begin{array}{l}\text { Midwest } \\
N=36,169 \\
(17.5 \%)\end{array}$ & $\begin{array}{c}\text { Northeast } \\
N=57,628 \\
(27.9 \%)\end{array}$ & $\begin{array}{l}\text { South } \\
N=89,066 \\
(43.1 \%)\end{array}$ & $\begin{array}{l}\text { West } \\
N=23,302 \\
\quad(11.3 \%)\end{array}$ & $\begin{array}{l}\begin{array}{l}\text { Other } \\
\text { regions }\end{array} \\
N=309 \\
(0.1 \%)\end{array}$ \\
\hline \multicolumn{7}{|l|}{ Age (years) } \\
\hline Mean (SD) & $47.9(12.7)$ & $45.9(12.7)$ & $48.9(12.6)$ & $48.0(12.6)$ & $48.3(12.7)$ & $49.5(11.7)$ \\
\hline Median & 50 & 47 & 51 & 50 & 50 & 50 \\
\hline \multicolumn{7}{|l|}{ Age group, $N \%$} \\
\hline $18-44$ years & $75,678(36.7)$ & $15,441(42.7)$ & $19,237(33.4)$ & $32,487(36.5)$ & $8420(36.1)$ & $93(30.1)$ \\
\hline $45-54$ years & $61,924(30.0)$ & $10,559(29.2)$ & $17,303(30.0)$ & $27,013(30.3)$ & $6943(29.8)$ & $106(34.3)$ \\
\hline 55-64 years & $51,920(25.2)$ & $8070(22.3)$ & $15,722(27.3)$ & $22,254(25.0)$ & $5791(24.9)$ & 83 (26.9) \\
\hline$\geq 65$ years & $16,952(8.2)$ & $2099(5.8)$ & $5366(9.3)$ & $7312(8.2)$ & $2148(9.2)$ & $27(8.7)$ \\
\hline \multicolumn{7}{|l|}{ Gender, $N \%$} \\
\hline Female & $54,938(26.6)$ & 7903 (21.9) & $17,638(30.6)$ & $25,845(29.0)$ & $3431(14.7)$ & $121(39.2)$ \\
\hline Male & $\begin{array}{r}151,536 \\
(73.4)\end{array}$ & $28,266(78.2)$ & $39,990(69.4)$ & $63,221(71.0)$ & $19,871(85.3)$ & $188(60.8)$ \\
\hline \multicolumn{7}{|l|}{$\begin{array}{l}\text { Race/ethnicity, } \\
\quad N \%\end{array}$} \\
\hline Caucasian & $61,829(30.0)$ & $12,798(35.4)$ & $14,450(25.1)$ & $25,272(28.4)$ & $9307(39.9)$ & $2(0.7)$ \\
\hline $\begin{array}{l}\text { Black/African } \\
\text { American }\end{array}$ & $54,849(26.6)$ & $10,453(28.9)$ & $14,266(24.8)$ & $29,164(32.7)$ & $966(4.2)$ & $0(0)$ \\
\hline Hispanic & $21,813(10.6)$ & $1676(4.6)$ & $9092(15.8)$ & $8413(9.5)$ & $2631(11.3)$ & $1(0.3)$ \\
\hline Asian & $1256(0.6)$ & $167(0.5)$ & $385(0.7)$ & $411(0.5)$ & $293(1.3)$ & $0(0)$ \\
\hline Unknown/other & $66,727(32.3)$ & $11,075(30.6)$ & $19,435(33.7)$ & $25,806(29.0)$ & $10,105(43.4)$ & $306(99.0)$ \\
\hline \multicolumn{7}{|l|}{$\begin{array}{l}\text { Insurance type, } \\
\quad N \%\end{array}$} \\
\hline Commercial & $78,996(38.3)$ & $15,227(42.1)$ & $17,683(30.7)$ & $38,264(43.0)$ & $7776(33.4)$ & $46(14.9)$ \\
\hline Medicaid & $63,020(30.5)$ & $12,139(33.6)$ & $22,683(39.4)$ & $20,685(23.2)$ & $7271(31.2)$ & $242(78.3)$ \\
\hline Medicare & $40,927(19.8)$ & $6224(17.2)$ & $10,201(17.7)$ & $19,833(22.3)$ & $4655(20.0)$ & $14(4.5)$ \\
\hline $\begin{array}{l}\text { Other/ } \\
\text { unspecified }\end{array}$ & $23,531(11.4)$ & $2579(7.1)$ & $7061(12.3)$ & $10,284(11.6)$ & $3600(15.4)$ & $7(2.3)$ \\
\hline
\end{tabular}

$S D$ standard deviation

a "Other regions" included US territories or military bases not included in the US census regions, etc. 
Table 2 Clinical characteristics of study population, overall and stratified by US region

\begin{tabular}{|c|c|c|c|c|c|c|}
\hline Characteristic & $\begin{array}{l}\text { All } \\
N=206,474\end{array}$ & $\begin{array}{l}\text { Midwest } \\
N=36,169\end{array}$ & $\begin{array}{l}\text { Northeast } \\
N=57,628\end{array}$ & $\begin{array}{l}\text { South } \\
N=89,066\end{array}$ & $\begin{array}{l}\text { West } \\
N=23,302\end{array}$ & $\begin{array}{l}\text { Other } \\
\text { regions }^{\text {a }} \\
N=309\end{array}$ \\
\hline \multicolumn{7}{|l|}{ CCI score ${ }^{b}$} \\
\hline Mean (SD) & $0.8(1.5)$ & $0.7(1.4)$ & $0.9(1.5)$ & $0.9(1.5)$ & $0.7(1.3)$ & $0.9(1.3)$ \\
\hline \multicolumn{7}{|l|}{ CCI score group, $N(\%)$} \\
\hline $\mathrm{CCI}=0$ & $126,244(61.1)$ & $23,316(64.5)$ & $33,398(58.0)$ & $53,882(60.5)$ & $15,481(66.4)$ & $167(54.1)$ \\
\hline $\mathrm{CCI}=1-2$ & $57,918(28.1)$ & $9469(26.2)$ & $17,159(29.8)$ & $25,322(28.4)$ & $5863(25.2)$ & $105(34.0)$ \\
\hline $\mathrm{CCI}=3-4$ & $15,017(7.3)$ & $2299(6.4)$ & $4745(8.2)$ & $6623(7.4)$ & $1320(5.7)$ & $30(9.7)$ \\
\hline $\mathrm{CCI} \geq 5$ & $7295(3.5)$ & $1085(3.0)$ & $2326(4.0)$ & $3239(3.6)$ & $638(2.7)$ & $7(2.3)$ \\
\hline \multicolumn{7}{|c|}{ Comorbid condition, ${ }^{\mathrm{c}} N(\%)$} \\
\hline Depressive disorders & $30,499(14.8)$ & $5659(15.7)$ & $9344(16.2)$ & $12,378(13.9)$ & $3092(13.3)$ & $26(8.4)$ \\
\hline Anxiety disorders & $23,297(11.3)$ & $4436(12.3)$ & $6539(11.4)$ & $9611(10.8)$ & $2691(11.6)$ & $20(6.5)$ \\
\hline Hyperlipidemia & $51,907(25.1)$ & $7228(20.0)$ & $14,732(25.6)$ & $24,412(27.4)$ & $5423(23.3)$ & $112(36.3)$ \\
\hline Type 2 diabetes & $24,926(12.1)$ & $3515(9.7)$ & $8037(14.0)$ & $11,157(12.5)$ & $2167(9.3)$ & $50(16.2)$ \\
\hline Substance abuse & $22,513(10.9)$ & $3979(11.0)$ & $8338(14.5)$ & $7768(8.7)$ & $2414(10.4)$ & $14(4.5)$ \\
\hline
\end{tabular}

$C C I$ Charlson Comorbidity Index, $S D$ standard deviation

a "Other regions" included US territories or military bases not in the US census regions, etc.

${ }^{b}$ CCI calculated without HIV/AIDS diagnoses

c Comorbid conditions with $\geq 10 \%$ prevalence reported

(per defined MTR above) or 1 STR, divided by the number of days in the follow-up period (i.e., 365 days). Values for PDC range from 0 to 100\% with higher values indicating higher adherence and "100\%" indicating a patient who had complete ART medication adherence. The PDC was determined for all patients in the study population and stratified by US region and state. Additionally, the percentages of patients with adherence levels of $<80 \%, 80 \%$ to $<90 \%$, and $\geq 90 \%$ (optimal adherence) were reported.

\section{Sensitivity Analyses}

A sensitivity analysis was conducted on adherence to ART that only included patients who were newly treated with ART (i.e., no ART medication use during the 12-month baseline period).

\section{Statistical Analyses}

For the descriptive analyses in this study, means and standard deviations (SD) were reported for continuous variables and counts and percentages for categorical variables. All data analyses were conducted using SAS ${ }^{\circledR} 9.4$ (SAS Institute, Cary, NC USA).

\section{RESULTS}

\section{Patient Characteristics}

The overall study population included 206,474 PWH treated with ART; $17.5 \%$ resided in the Midwest, $27.9 \%$ in the Northeast, $43.1 \%$ in the South, $11.3 \%$ in the West, and $0.1 \%$ in other regions (US territories or military bases not included in the US census regions, etc.). Most patients $(81.7 \%)$ had at least one prior ART 
Table 3 Adherence to ART during the 12-month followup period, overall and stratified by US region

\begin{tabular}{lllll}
\hline & & \multicolumn{2}{l}{ PDC \% } & \\
\cline { 3 - 5 } \cline { 3 - 5 } & & Mean & SD & Median \\
\hline All & 74.1 & 25.9 & 84.9 \\
Midwest & & 74.4 & 25.5 & 84.9 \\
Northeast & 74.3 & 26.1 & 85.5 \\
South & 73.2 & 26.3 & 84.1 \\
West & 76.4 & 24.8 & 87.1 \\
Other regions & 73.2 & 22.2 & 80.3 \\
\hline
\end{tabular}

$A R T$ antiretroviral therapy, $P D C$ proportion of days covered, $S D$ standard deviation

treatment in the baseline period (ART experienced) and a majority (68.8\%) used an STR as their index ART.

Patient demographic and clinical characteristics are shown in Tables 1 and 2, respectively, for the overall study population and stratified by US region. Among the overall study population, mean age was 47.9 years, $73.4 \%$ were male, $30.0 \%$ were Caucasian, and $26.6 \%$ were Black/African American. Over one-third (38.3\%) had commercial insurance, 30.5\% were covered by Medicaid, and $19.8 \%$ by Medicare. CCI scores were generally low (mean: 0.8) after excluding HIV/AIDS diagnoses. Comorbid conditions with $\geq 10 \%$ prevalence in the overall study population included hyperlipidemia (25.1\%), depressive disorders $(14.8 \%)$, type 2 diabetes (12.1\%), anxiety disorders (11.3\%), and substance abuse (10.9\%).

\section{Adherence to ART}

During the 12-month follow-up, mean (SD) PDC was $74.1 \%$ (25.9\%) among all PWH across the US included in the study; in the Midwest mean (SD) PDC was $74.4 \%(25.5 \%)$, in the Northeast it was $74.3 \%(26.1 \%)$, in the South it was $73.2 \%(26.3 \%)$, in the West it was $76.4 \%$ $(24.8 \%)$, and in other regions it was $73.2 \%$ (22.2\%) (Table 3).

Adherence levels across all US states are shown in Fig. 2 and Supplementary Table 1.

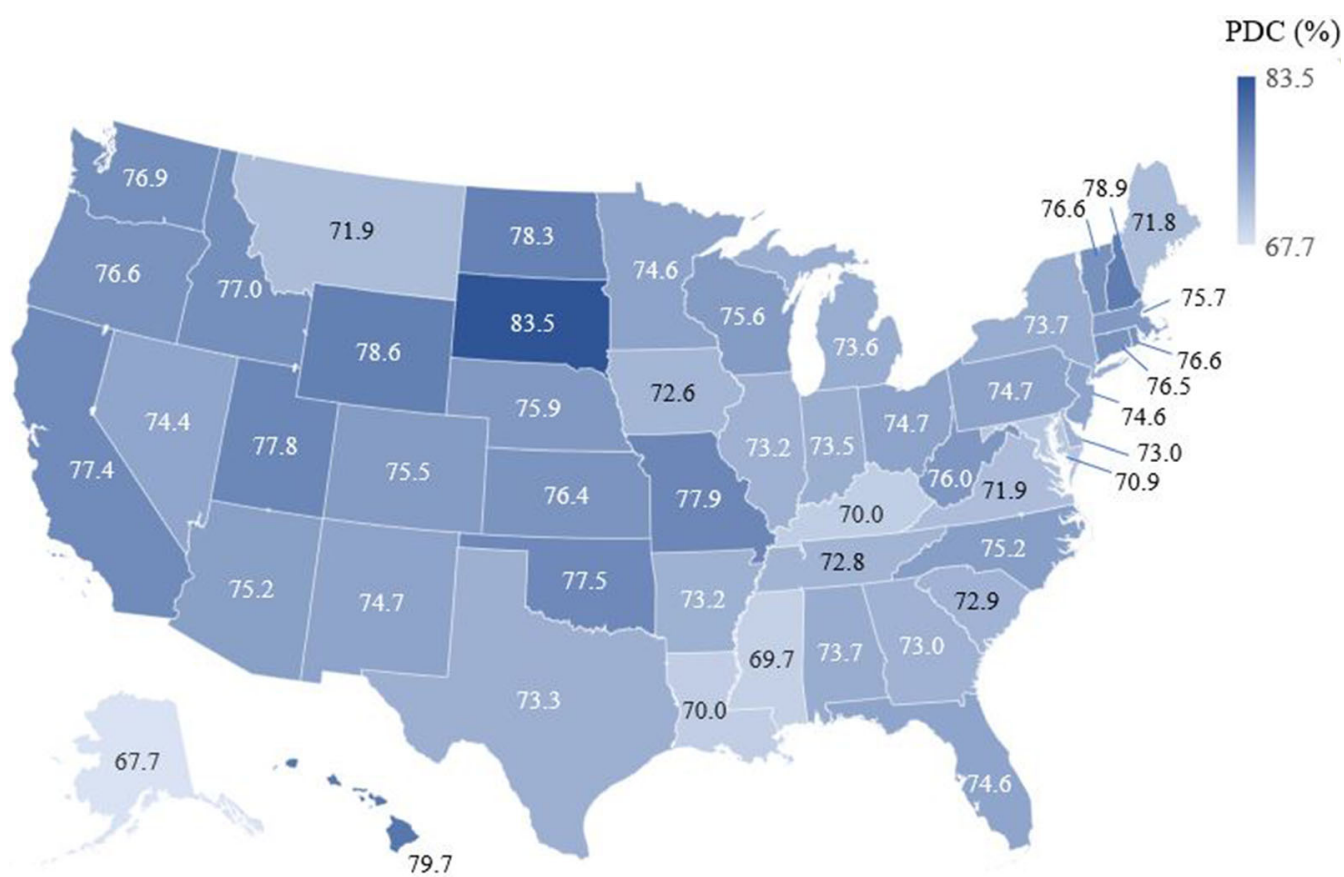

Fig. 2 Mean adherence to ART during the 12-month follow-up period stratified by US state. ART antiretroviral therapy, $P D C$ proportion of days covered 


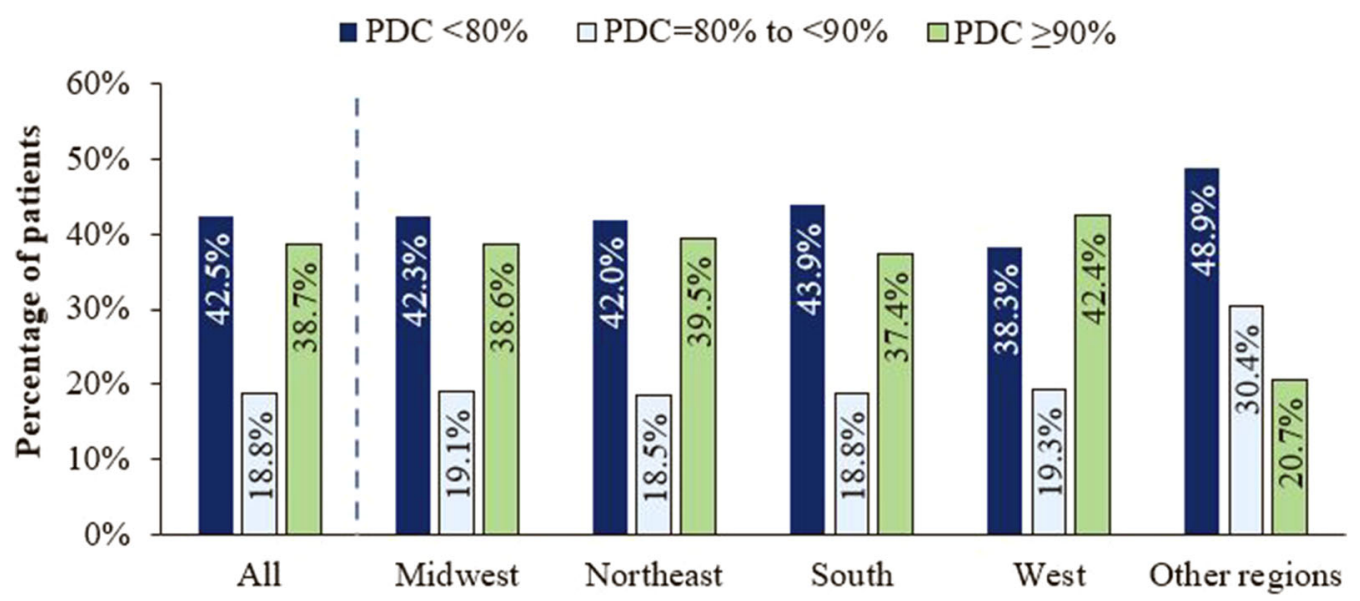

Fig. 3 Adherence to ART during the 12-month follow-up period, overall and stratified by US region. $A R T$ antiretroviral therapy, $P D C$ proportion of days covered

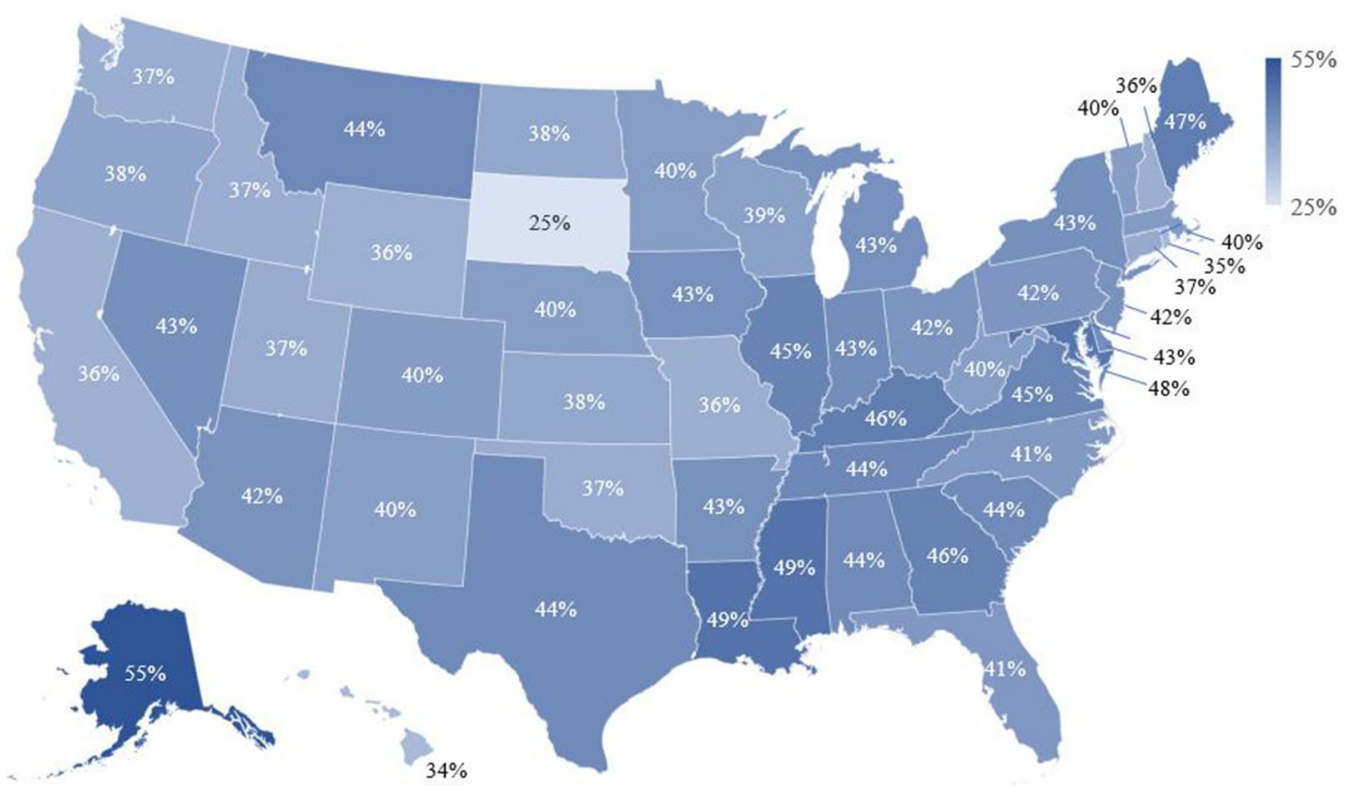

Fig. 4 Percentage of PWH with poor adherence to ART (PDC $<80 \%$ ) during the 12-month follow-up period stratified by US state. ART antiretroviral therapy, $P W H$ patients with HIV-1

Mean adherence to ART ranged from $67.7 \%$ in Alaska to $83.5 \%$ in South Dakota. The five states with the highest average adherence to ART were South Dakota $(83.5 \%)$, Hawaii $(79.7 \%)$, New Hampshire $(78.9 \%)$, Wyoming $(78.6 \%)$, and North Dakota (78.3\%). The five states with the lowest average adherence to ART were Alaska (67.7\%), Mississippi (69.7\%), Kentucky (70.0\%), Louisiana (70.0\%), and Maryland (70.9\%).
Among all PWH included in the study population, $38.7 \%$ had optimal adherence (PDC $\geq 90 \%), 18.8 \%$ had PDC $=80 \%$ to $<90 \%$, and $42.5 \%$ had PDC $<80 \%$ (Fig. 3). Across US regions, the percentage of $\mathrm{PWH}$ with adherence to ART $<90 \%$ ranged from $57.6 \%$ in the West to $62.6 \%$ in the South; $38.3-43.9 \%$ had poor adherence (PDC < 80\%) (Fig. 3).

Figure 4 shows the percentage of PWH with poor adherence $(\mathrm{PDC}<80 \%)$ stratified by US 


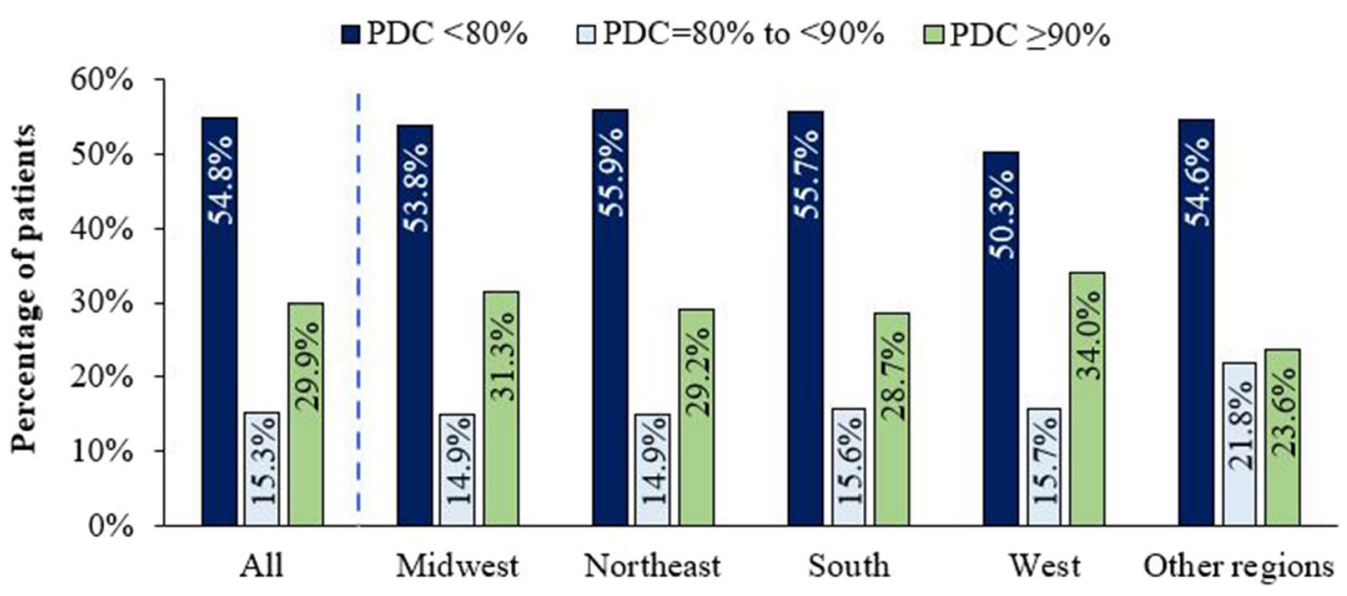

Fig. 5 Sensitivity analysis of newly ${ }^{a}$ treated PWH: adherence to ART during the 12-month follow-up period, overall and stratified by US region. $A R T$ antiretroviral

state. The five states with the lowest percentages of patients with PDC $<80 \%$ were South Dakota (25\%), Hawaii (34\%), Rhode Island (35\%), California (36\%), and Wyoming (36\%). The five states with the highest percentages of patients with PDC $<80 \%$ were Alaska (55\%), Mississippi (49\%), Louisiana (49\%), Maryland (48\%), and Maine (47\%).

\section{Sensitivity Analyses}

In the sensitivity analysis of patients who did not have any prior ART use during the baseline period (i.e., newly treated with ART), 37,825 were included (mean age: 44.8 years; $71.8 \%$ male; Supplementary Table 2). A majority (72.8\%) used an STR as their index ART. Among this population subset, mean (SD) PDC was 64.2\% (31.0\%; median: 74.8\%) and lower than the overall study population; $29.9 \%$ had optimal adherence (PDC $\geq 90 \%), \quad 15.3 \%$ had $\mathrm{PDC}=80 \%$ to $<90 \%$, and $54.8 \%$ had poor adherence (PDC $<80 \%$ ) (Fig. 5). Across US regions, the percentage of newly treated $\mathrm{PWH}$ with adherence to ART $<90 \%$ ranged from $66.0 \%$ in the West to $71.3 \%$ in the South; $50.3-55.9 \%$ had poor adherence (PDC $<80 \%$ ) (Fig. 5). therapy, $P D C$ proportion of days covered, $P W H$ patients

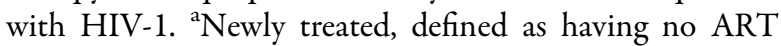
medication use during the 12 -month baseline period

\section{DISCUSSION}

In this large retrospective US study including > 200,000 PWH who were treated with ART during July 2017 through September 2019, we found that the average adherence to therapy was approximately $74 \%$, with those in the West having the highest mean adherence (76\%) and those in the South, the lowest (73\%). A majority (approximately 60\%) of PWH had suboptimal adherence (PDC $<90 \%$ ) to ART and $42 \%$ had poor adherence (PDC $<80 \%$ ). In a prior nationwide US study of $169,545 \mathrm{PWH}$ treated with ART during January 2015 through September 2017 who were also selected from the IDV database, Benson et al. [16] reported an average adherence of $72 \%$. Among this patient population, $25 \%$ had optimal adherence, defined as having PDC $\geq 95 \%$, and $45 \%$ exhibited poor adherence (PDC $<80 \%$ ) [16]. Thus, adherence to ART among PWH in the US has remained relatively stable during years 2015 to 2019, with slightly fewer PWH exhibiting poor adherence to ART during the time period of the current study. These study findings imply that the recent introduction of STRs does not seem to have considerably impacted adherence to ART.

The mean adherence level to ART observed in this study is lower than found in some other prior studies with sample sizes that were 
relatively large, but inclusive of patients with less generalizable characteristics $[17,18]$. In a retrospective study by Youn et al. [17], 23,343 PWH insured by Medicaid in 14 US states with high HIV prevalence were included; a majority were younger than 44 years of age, approximately one-third were from the state of New York and 15\% resided in California and 10\% in Florida. Youn et al. [17] reported that from 2001 to 2010, the percentage of patients who initiated ART who had $>90 \%$ adherence, measured as ART implementation, increased from 33.5 to $52.4 \%$. For comparison, in our study population, only $39 \%$ of the patients had a PDC $\geq 90 \%$. In a study of commercially and Medicare Advantage-insured PWH $(N=25,320$; mean age: 45 years; $43 \%$ from the South) identified between 2010 and 2014, the reported mean PDC was $82 \%$ among those on $\geq 2$ ART medications and $25 \%$ had poor adherence [18]. The higher adherence to ART observed in these studies may be related to several factors, including differences in patient demographic characteristics, study years, data sources, methods of measuring adherence, and insurance types. Another claims-based study of 1698 commercially insured PWH and 332 Medicaidcovered PWH who initiated ART between 2007 and 2014 reported 15-month mean adherence levels, measured by PDC, of $79 \%$ among those commercially insured and 65\% among those covered by Medicaid [14]; although follow-up durations differed, these findings are more similar to our study.

In the sensitivity analysis of patients newly treated with ART, we observed a 10\% lower average adherence to ART compared with the overall study population ( $64 \%$ vs. $74 \%)$. The patients included in this sensitivity analysis were younger than the overall study population (mean age: 45 vs. 48 years; $47 \%$ vs. $37 \%$ were between 18 and 44 years of age, respectively); similarly, a greater percentage was covered by Medicaid (37\% vs. 31\%) and fewer by Medicare (14\% vs. $20 \%$ ). There were also some differences in the race/ethnicity distribution among those newly treated with ART; the percentage of Caucasians was lower (25\% vs. 30\%), but the percentage of those with unknown/other race/ ethnicity was higher (38\% vs. 32\%). Benson et al. [16] also assessed social determinants of adherence and found that poor adherence to ART was associated with non-Caucasian race, unemployment, no health insurance, lower educational status, and those without linkage to care. Another study of 2633 PWH (2017-2019) also observed that younger age was a predictor of low ART adherence [19]. The findings of these studies and ours may be helpful for targeting and tailoring efforts to improve adherence to ART among persons who are newly treated with ART. However, since we defined "newly treated with ART" as no ART use during the 12-month baseline period, this patient group may have been comprised of those who initiated their first ART regimen during the study identification period and also those who had been potentially non-adherent to their prior ART medications and had a long interruption (i.e., at least 12 months) in therapy prior to restarting ART. The latter patient subset may have biased this patient group toward lower adherence.

Our study population was generally young, with $37 \%$ being $18-44$ years of age and most were male (73\%). These characteristics are relatively similar to the study population of Benson et al. [16] in which $40 \%$ were $18-44$ years of age and $73 \%$ were male. Among our study population, there was good representation of patients with different races/ethnicities (Caucasian: 30\%; Black/African American: 27\%; Hispanic: 11\%; unknown/other: 32\%) and insurance types [commercial: 38\%; Medicaid: 31\%; Medicare: $20 \%$; other smaller categories of insurance types/unspecified insurance type (may include some uninsured $\mathrm{PWH}$ ): $11 \%]$. This distribution of insurance types is somewhat different from that of the study population of Benson et al. [16] (commercial: 25\%; Medicaid: 31.5\%; Medicare: $18 \%$ ). This may be related to the data source year and data processes of the IDV database, since in our study a lower proportion of patients were found to have other/unspecified insurance types than in Benson et al. [16] (11\% vs. 17\%). Future studies may be warranted on how age, race/ethnicity, and insurance type affect adherence to ART to better target intervention efforts.

Currently, the threshold of optimal adherence to ART is in debate, most notably because 
newer ART regimens may achieve sustained viral suppression with lower levels of adherence $[7,20,21]$. Defining optimal adherence to ART is critical since suboptimal adherence can lead to virologic failure and the development of HIV drug resistance [10]. The success of ART is not only measured in sustained viral suppression and improving clinical outcomes of PWH, but also in preventing the emergence of viral resistance to HIV drugs, a transmissible consequence of inadequate viral suppression. Using the Monogram/LabCorp database, Benson et al. [16] also examined HIV-1 drug resistance rates in the US and found that they were exceptionally high in most states, ranging between 20 and 54\%, with some of the states with the highest rates of HIV drug resistance also having relatively high rates of poor adherence to ART. Improving ART adherence, population testing for HIV drug resistance and HIV genotyping, as well as the use of ART regimens with high genetic barriers to resistance are all strategies worth implementing to achieve sustained viral suppression $[22,23]$. ART regimens with high genetic barriers to resistance refers to those that maintain optimal viral suppression in the presence and accumulation of resistance-associated viral mutations. These ART regimens may be particularly beneficial to PWH who have suboptimal adherence [24] and are recommended in the DHHS guidelines for such patients [10].

The findings of this retrospective observational study should be interpreted in the context of certain limitations. First, adherence to ART was calculated based on prescription fills and pharmacy records. Because it is not possible to confirm whether a patient actually took their medication as prescribed, adherence to ART may have been overestimated in this study; however, our study findings highlight a concerning prevalence of suboptimal adherence in the US. Second, while our study population included patients from all US Census Bureau designated regions and all major US insurance types were well represented, our study findings may not be generalizable to $\mathrm{PWH}$ defined by more specific demographics, such as those residing in rural areas, or those who are uninsured or have interrupted coverage. Additionally, this study examined adherence to ART regimens among PWH prior to the COVID-19 pandemic, which may have recently affected adherence levels.

The IDV database consolidates data from multiple healthcare suppliers, but it may not have captured all medical and pharmacy records for the patients included in this study. Also, the data source contains limited information on laboratory testing data on the level of viral suppression and drug resistance of HIV patients. Therefore, these outcomes could not be examined in this study. While in this study we analyzed adherence to ART at the national, regional, and state levels using descriptive statistics, as well as conducted a sensitivity analysis of only PWH newly treated with ART, future studies may be warranted on how age, race/ethnicity, insurance types, comorbidities, and different ART regimens/medications affect adherence levels using multivariable analyses.

Since the data source is not insurance claimsbased, there was no insurance enrollment status data available. Thus, we used an inclusion criterion that required medical or pharmacy activity during the follow-up period as a proxy for continuous enrollment. In doing so, patients who died within 12 months of the index date or who were lost to follow-up for any other reason were excluded from the study. Despite these limitations, the number of $\mathrm{PWH}$ included in this study was $>200,000$ with patients represented in every US state. Thus, the findings on adherence to ART described herein may be helpful toward guiding efforts to optimize adherence in the continuum of care of patients with HIV-1 at the national, regional, and state levels.

\section{CONCLUSIONS}

This large nationwide US study, including > 200,000 patients with HIV-1, found that adherence to ART was suboptimal or poor for $>$ $60 \%$ of patients, with some small variations in adherence observed across US regions. More intensive implementation of interventions to improve ART adherence is needed in the US. As outlined by the DHHS [10], such interventions may include providing uninterrupted access to 
care, the periodic assessment of adherence to ART and care, patient education on the importance of adherence, and clinical consideration in the selection of ARTs with high genetic barriers to resistance for patients at risk of developing HIV-1 drug resistance because of low adherence.

\section{ACKNOWLEDGEMENTS}

The author team would like to thank Wing Chow, PharmD, MPH, a former employee of Janssen Scientific Affairs, LLC, for her contributions to the study design and study protocol.

Funding. This research, preparation of this manuscript, rapid service/open access fees, and article processing charges were sponsored by Janssen Scientific Affairs, LLC.

Authorship. All named authors meet the International Committee of Medical Journal Editors (ICMJE) criteria for authorship for this article, take responsibility for the integrity of the work as a whole, and have given their approval for this version to be published.

Authorship contributions. Grace A. McComsey, Rachel Rogers, Jay Lin, and Prina Donga contributed to the conception and study design. Grace A. McComsey, Melissa LingohrSmith, Rachel Rogers, Jay Lin, and Prina Donga contributed to the data analyses and interpretation and the drafting and revising of the manuscript.

Prior presentation. Some aspects of this research were previously presented as a poster presentation at the live virtual American Conference for the Treatment of HIV (ACTHIV), May 20-22, 2021.

Disclosures. Grace a McComsey is a consultant to Janssen Scientific Affairs, Gilead, Theratechnologies, Merck, and ViiV/ GlaxoSmithKline, and has received grant funding from Roche, Genentech, Merck, Gilead, Astellas, Tetraphase, RedHill, and Vanda. Rachel Rogers and Prina Donga are employees of
Janssen Scientific Affairs, LLC and may be stockholders in Johnson \& Johnson. Melissa Lingohr-Smith and Jay Lin are employees of Novosys Health, which received research funds from Janssen Scientific Affairs, LLC in connection with conducting this study and preparation of this manuscript.

Compliance with ethics guidelines. The data source used for this study is comprised of administrative healthcare records that are deidentified and certified to be fully compliant with the Health Insurance Portability and Accountability Act patient confidentiality requirements. Institutional review board approval to conduct this study was not required because the study used only deidentified patient records and did not involve the collection, use, or transmittal of individually identifiable data.

Data availability. All data generated or analyzed during this study are included in this published article, or as supplementary material, or are available upon request from the corresponding author.

Open Access. This article is licensed under a Creative Commons Attribution-NonCommercial 4.0 International License, which permits any non-commercial use, sharing, adaptation, distribution and reproduction in any medium or format, as long as you give appropriate credit to the original author(s) and the source, provide a link to the Creative Commons licence, and indicate if changes were made. The images or other third party material in this article are included in the article's Creative Commons licence, unless indicated otherwise in a credit line to the material. If material is not included in the article's Creative Commons licence and your intended use is not permitted by statutory regulation or exceeds the permitted use, you will need to obtain permission directly from the copyright holder. To view a copy of this licence, visit http://creativecommons.org/licenses/by$\mathrm{nc} / 4.0 /$. 


\section{REFERENCES}

1. Harris NS, Johnson AS, Huang Y-LA, et al. Vital signs: status of human immunodeficiency virus testing, viral suppression, and HIV preexposure prophylaxis-United States, 2013-2018. MMWR Morb Mortal Wkly Rep. 2019;68:1117-23.

2. Centers for Disease Control and Prevention. Table 11. Human immunodeficiency virus (HIV) diagnoses, by year of diagnosis and selected characteristics: United States, 2013-2018. https://www. cdc.gov/nchs/data/hus/2019/011-508.pdf. Accessed 22 Mar 2021.

3. Centers for Disease Control and Prevention. HIV surveillance report. Last updated June 2020. https:// www.cdc.gov/hiv/statistics/overview/index.html. Accessed 22 Mar 2021.

4. Poorolajal J, Hooshmand E, Mahjub H, Esmailnasab N, Jenabi E. Survival rate of AIDS disease and mortality in HIV-infected patients: a meta-analysis. Public Health. 2016;139:3-12.

5. Teeraananchai S, Kerr SJ, Amin J, Ruxrungtham K, Law MG. Life expectancy of HIV-positive people after starting combination antiretroviral therapy: a meta-analysis. HIV Med. 2017;18:256-66.

6. Cohen MS, Chen YQ, McCauley M, et al. Antiretroviral therapy for the prevention of HIV-1 transmission. N Engl J Med. 2016;375:830-9.

7. Altice F, Evuarherhe O, Shina S, Carter G, Beaubrun AC. Adherence to HIV treatment regimens: systematic literature review and meta-analysis. Patient Prefer Adherence. 2019;13:475-90.

8. Pharmacy Quality Alliance. PQA Measure Overview. 2019. https://www.pqaalliance.org/assets/ Measures/2019_PQA_Measure_Overview.pdf. Accessed 22 Mar 2021.

9. US Department of Health and Human Services. Guidelines for the use of antiretroviral agents in adults and adolescents living with HIV. Treatment goals. Updated January 28, 2016. https:// clinicalinfo.hiv.gov/en/guidelines/adult-andadolescent-arv/treatment-goals?view=full. Accessed 18 May 2021.

10. Panel on Antiretroviral Guidelines for Adults and Adolescents. Guidelines for the use of antiretroviral agents in adults and adolescents with HIV. https:// clinicalinfo.hiv.gov/sites/default/files/guidelines/ documents/AdultandAdolescentGL.pdf. Accessed 18 May 2021.

11. Sutton SS, Hardin JW, Bramley TJ, D'Souza AO, Bennett CL. Single- versus multiple-tablet HIV regimens: adherence and hospitalization risks. Am J Manag Care. 2016;22:242-8.

12. Yager J, Faragpm J, McGuey L, et al. Relationship between single tablet antiretroviral regimen and adherence to antiretroviral and non-antiretroviral medications among Veterans' Affairs patients with human immunodeficiency virus. AIDS Patient Care STDs. 2017;31:370-6.

13. Hines DM, Ding Y, Wade RL, Beaubrun A, Cohen JP. Treatment adherence and persistence among HIV-1 patients newly starting treatment. Patient Pref Adherence. 2019;13:1927-39.

14. Kangethe A, Polson M, Lord TC, Evangelatos T, Oglesby A. Real-world health plan data analysis: key trends in medication adherence and overall costs in patients with HIV. J Manag Care Spec Pharm. 2019;25:88-93.

15. Cohen J, Beaubrun A, Bashyal R, Huang A, Li J, Baser $\mathrm{O}$. Real-world adherence and persistence for newly-prescribed HIV treatment: single versus multiple tablet regimen comparison among US medicaid beneficiaries. AIDS Res Ther. 2020;17:12.

16. Benson C, Wang X, Dunn KJ, et al. Antiretroviral adherence, drug resistance, and the impact of social determinants of health in HIV-1 patients in the US. AIDS Behav. 2020;24:3562-73.

17. Youn B, Shireman TI, Lee Y, Galárraga O, Wilson IB. Trends in medication adherence in HIV patients in the US, 2001 to 2012: an observational cohort study. J Int AIDS Soc. 2019;22: e25382.

18. Forlenza J, Brown K, Shprecher A, et al. An evaluation of patient characteristics, duration on antiretrovirals (ARVs) and adherence in a large, insured United States population receiving HIV treatment between 2010 and 2014. Open Forum Infect Dis. 2015;2:416.

19. Chow W, Donga P, Côté-Sergen A, et al. Treatment patterns and predictors of adherence in HIV patients receiving single- or multiple-tablet darunavir, cobicistat, emtricitabine, and tenofovir alafenamide. Patient Prefer Adherence. 2020;14: 2315-26.

20. Bezabhe WM, Chalmers L, Berznicki LR, Peterson GM. Adherence to antiretroviral therapy and virologic failure. Medicine (Baltimore). 2016;95: e3361.

21. Byrd KK, Hou JG, Hazen R, et al. Antiretroviral adherence level necessary for HIV viral suppression using real-world data. J Acquir Immune Defic Synd. 2019;82:245-51.

22. Aldous AM, Castel AD, Parenti DM. DC Cohort Executive Committee. Prevalence and trends in 
transmitted and acquired antiretroviral drug resistance, Washington, DC, 1999-2014. BMC Res Notes. 2017;10:474.

23. Scherrer AU, von Wyl V, Yang WL, et al. Emergence of acquired HIV-1 drug resistance almost stopped in Switzerland: a 15-Year prospective cohort analysis. Clin Infect Dis. 2016;62:1310-7.
24. Lathouwers E, Wong EY, Brown $\mathrm{K}$, et al. Week 48 resistance analyses of the once-daily, single-tablet regimen darunavir/cobicistat/emtricitabine/tenofovir alafenamide $(\mathrm{D} / \mathrm{C} / \mathrm{F} / \mathrm{TAF})$ in adults living with HIV-1 from the Phase III randomized AMBER and EMERALD trials. AIDS Res Hum Retroviruses. 2020;36:48-57. 